MATEC Web of Conferences 10, 01002 (2014)

DOI: $10.1051 /$ matecconf/ 20141001002

(C) Owned by the authors, published by EDP Sciences, 2014

\title{
Industrialised Building System in Malaysia: A Review
}

\author{
M.A. Othuman Mydin ${ }^{1, \text { a }, ~ N . ~ M d ~ S a n i ², ~ M . ~ T a i b ~}{ }^{3}$ \\ ${ }^{1,2,3}$ School of Housing, Building and Planning, Universiti Sains Malaysia, 11800, Penang, Malaysia
}

\begin{abstract}
The construction industry in Malaysia is experiencing a migration from conventional methods to a more systematic and mechanised method known as the Industrialised Building System (IBS). Each state in Malaysia is currently examining the developments of the IBS and its potential to overcome the shortages of housing accommodations in this country. The Malaysian government, involved through its agency, the Construction Industry Development Board (CIDB) has been persistently pushing the construction industry to utilise of the IBS method of construction since the year 2003. It is a part of an incorporated endeavour to further improve the aptitude, potential, effectiveness and competitiveness of the industry as well as to diminish the industry's dependence on foreign labour. This is also an attempt in the Malaysian construction industry to encourage positive inroads in matters associated to construction-site safety with regards to a working environment which is cleaner, more convenient and more organized.
\end{abstract}

\section{Introduction}

In Malaysia, the IBS was initiated since the 1960s, when the Ministry of Housing and Local Government made visits to several European municipalities with the objective of assessing their housing development plans. After a successful tour run in 1964, the Malaysian government launched a project to put to the test the efficiency of the IBS. This is to gauge its potential as a system that could be deployed as an alternative to the conventional system which already had a strong foothold in Malaysia [1]. The key objectives looking to be fulfilled include the acceleration as well as the increase of affordable housing of substantial quality here in Malaysia [2]. The IBS proved to be a success. Not only was it efficient in accelerating the construction of housing projects, it also improved the quality and affordability of the projects in which the IBS was deployed. Based on different reference materials accepted by authorities in the construction fraternity, we have several ways of defining the IBS [3]. Despite the IBS being well-known and accepted by most construction firms due to its theoretical advantage in terms of speed, safety and quality, wet construction method is still widely regarded in Malaysia as a conventional and safe option despite incurring higher costs and slower production rates.

Returning to the definition of the IBS, it is simply regarded as a construction technique in which components are manufactured in a controlled environment either on or off-site [4]. These are transported, positioned and assembled into a structure with the least of additional site work. The components of the IBS are materials that are produced in factories where quality control is not compromised on. This also minimises activities at the site of construction.

\footnotetext{
${ }^{a}$ Corresponding author: azree@usm.my
} 
Building components which are often used in the IBS projects include walls, floors, beams and staircases [5]. The IBS construction method can reduce wastage of resources besides providing good quality results for consumers [6]. The construction method of this type is an industrial process in which building components are designed, transported to the construction site and finally erected according to plans. It sometimes involves pertaining software which is a prerequisite in creating conducive environments for industrial development. The hardware elements which are involved in the IBS can be categorised into three main groups. These design systems are set up to study the needs of the end users, market analysis, improvements of establishment standards as well as the layout of manufacturing and installation work [7]

The Malaysian government often provides housing projects to the populace. For instance, about 800,000 affordable housing units were provisioned and expected to be provided under the 7 th Malaysian Plan in which 73.1\% were low and medium cost houses. However, reports of achievements are rare and only $20 \%$ of the envisioned figure have been reported despite the various initiatives implemented to encourage developers to invest in the housing sector [8]. Housing development projects continued in 2001 until 2005 under the 8th Malaysian Plan in which provisions were made for affordable and sustainable housing accommodations. The total target was set at between 600,000 to 800,000 units. In the 9th Malaysian Plan, 43,800 units of low-cost houses were built through several housing programmes while 29,000 units of low and medium-cost houses were built by the Syarikat Perumahan Negara Berhad [9]. The 10th Malaysian Plan also added to the access of quality and affordable housing with an increase of 161,000 new units which were owned and developed by public housing firms. These housing projects will contain elements of green building technologies and designs [10]. With the provisions set by the federal government, a problem will definitely be encountered due to the inability of conventional construction methods in coping with the demand for housing.

This is because Malaysia faces a shortage of labour. Therefore, the government has decided to introduce the use of pre-cast building materials in the construction industry. All civil construction projects are directed to apply at least $50 \%$ of the IBS approach in their endeavours. This will confer greater advantages in line with increased productivity, enhanced quality of the internal resistance besides being cost-cutting [11]. Works Minister Datuk Seri S. Samy Vellu said that the directive covers 26 projects worth RM2.4 billion proposed in the 9th Malaysian Plan (2006-2010) which have been approved for immediate action. Regarding the 10th Malaysian Plan, the government promises to provide affordable housing projects which are sustainable and which adhere to the green concept for all the projected 78,000 housing units in this plan indicating that the IBS construction method has to be fully implemented [12].

\section{Industrialised Building System History In Malaysia}

The IBS is not a new thing in the construction sector; the concept was introduced in as early as 1624, when the wood panel houses were brought from England to North America. The pyramids of Egypt were using the IBS concept where blocks are divided into smaller and more manageable sizes for easy transportation [13]. The turning point of constructions using the IBS was in the United Kingdom, particularly in the construction of the Crystal Palace which was built in 1851 (Figure 1). Frame components used were glass, wood and steel windows. Based on the SPI Survey, the construction of this building took only four months to complete [14].

In 1963, the Malaysian government sent architects from the Public Works Department (PWD) to several European countries to explore the concepts of development in these countries in further detail. At the same time, the Ministry of Housing and Local Government focused on housing development projects to improve the quality of life at that time. Representatives from Malaysia also visited Western nations such as Germany, Denmark and France for information on the construction industry [15] 


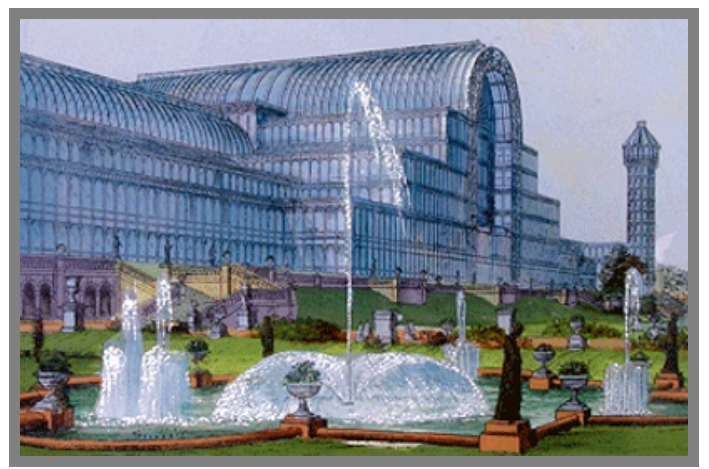

Figure 1. The Crystal Palace, London

Nowadays there are numerous mega-projects that deploy the Industrialised Building System and among these are the Petronas Twin Towers (Figure 2) Bukit Jalil Sports Complex and The Malaysian Light Rail Transit (Figure 3). Although this system had been introduced since nearly four decades ago in Malaysia, yet its applications are still at low levels. Enhancements of the infrastructure in the country allow the system to continue to expand in the future [16]

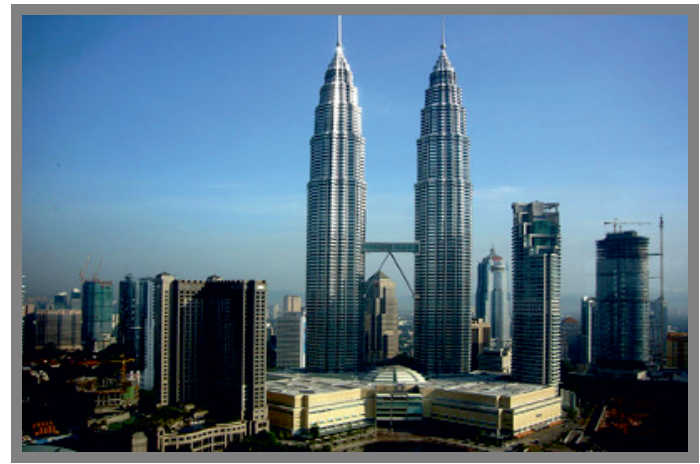

Figure 2. Petronas Twin Tower

Following the success of their visits, the government started major projects using the IBS system in 1964. Their main objective was to accelerate the completion of the projects on time besides being able to construct affordable housing units of substantial quality. Projects along the Jalan Pekeliling, Kuala Lumpur which were as wide as 22.7 acres included the construction of 7 blocks of flats of 17storeys each encompassing 3,000 low-cost flats and 40 shop lots (Figure 4). The project took two years and three months to complete, costing a total of RM 2.5 million for casting [16].
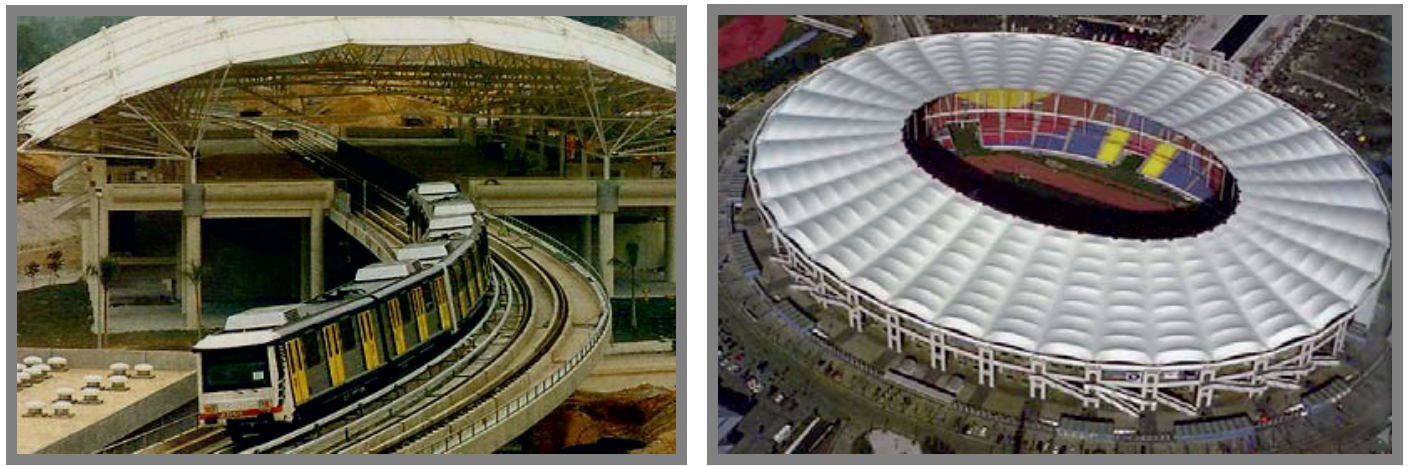

Figure 3. Light Rail Transit (left) and Bukit Jalil Sports Complex (right) 
The system can only be used for buildings with simple and easy designs. The use of the IBS in construction is getting better by the day. As reported, there are at least 21 different manufacturers and suppliers that are promoting their components in Malaysia. An IBS Centre has also been established in Jalan Chan Sow Lin, Cheras, Kuala Lumpur. These are the authorities who are responsible for implementing strategies and introducing breakthroughs in the IBS technology to improve its performance and quality in the construction industry as well as to reduce dependencies on foreign labour, avoiding the flooding of the local construction market with a foreign workforce.

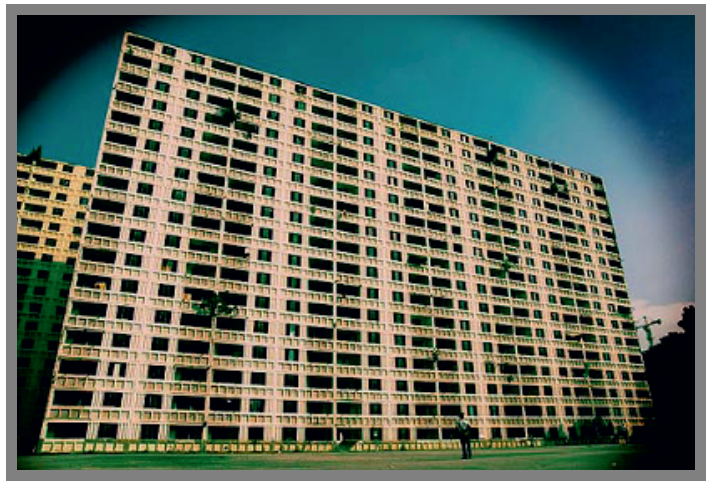

Figure 4. Jalan Pekeliling Flat, Kuala Lumpur

\section{Classification of the IBS}

There are generally five types of Industrialised Building System (IBS). These are:

\subsection{Precast concrete system (Walls, Slabs, Columns, 3D Components)}

Precast concrete system is the group that is most widely used in the IBS. It includes precast concrete columns, beams, slabs, walls, "3-D" components (e.g.: balconies, staircases (Figure 5), toilets, lift chambers, refuse chambers), lightweight precast concrete, as well as permanent concrete formworks.
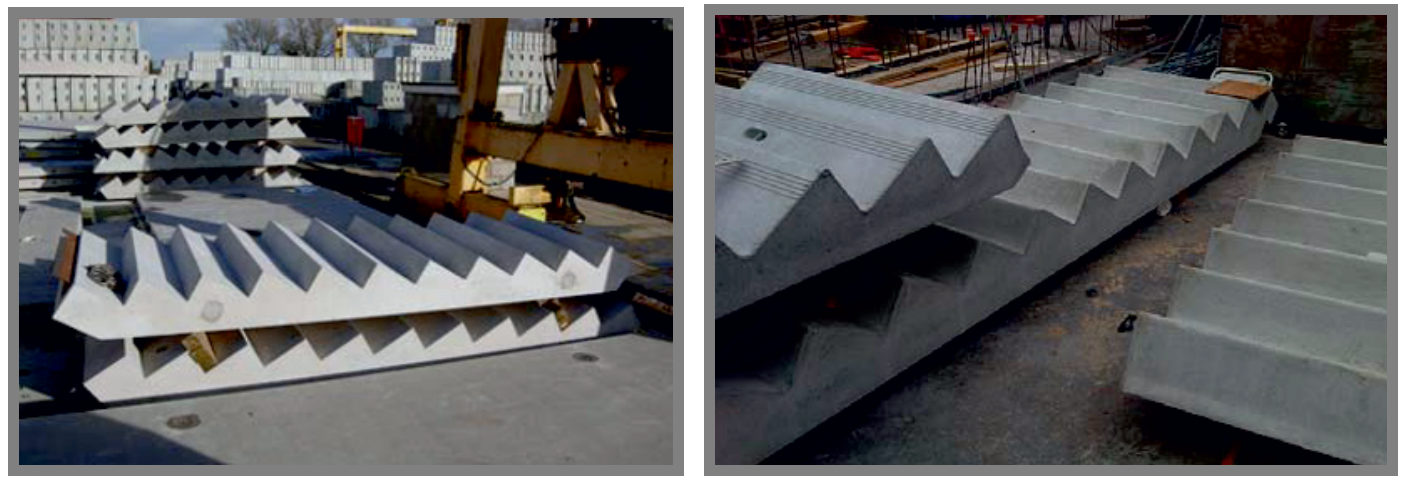

Figure 5. Precast Staircase

\subsection{Steel Formwork system}

Identified as one of the least prefabricated types of the IBS, it generally involves concrete at the construction site and high quality control. These products provide a high quality finish, faster construction and demand relatively less labour and materials. This includes the "tunnel form", the "lilt-up" beam system, "moulding form" columns (Figure 6) and a permanent steel mould. 

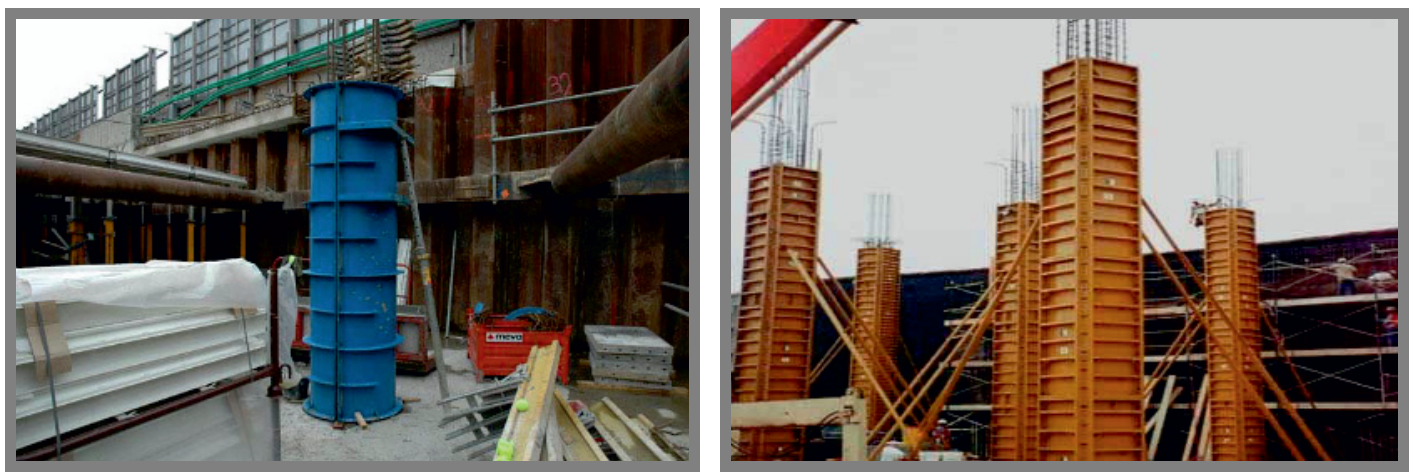

Figure 6. Steel formwork for Column

\subsection{Steel Framing System}

This system includes steel trusses (Figure 7), beams and a column portal frame system. It is frequently used with pre-cast concrete slabs, steel beams and columns as well as portal frame systems. It is always preferred and widely used in the constructions of skyscrapers and also in the constructions of large factories and exhibition halls that require wide areas.
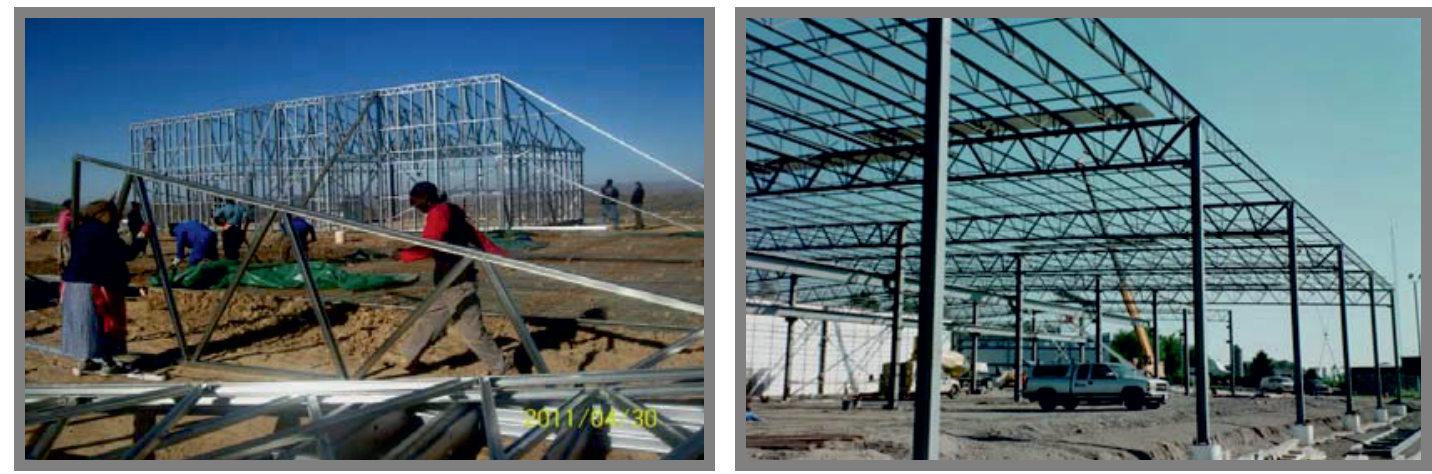

Figure 7. Lightweight steel frame system

\subsection{Prefabricated timber framing systems}

This system involves prefabricated timber truss beams and columns (Figure 8). Most of the products listed in this category are wooden building frames and roof trusses. It is quite popular and widely applicable as it provides attractive designs and high aesthetic values as chalets for resorts, contributing very much to the tourism industry.
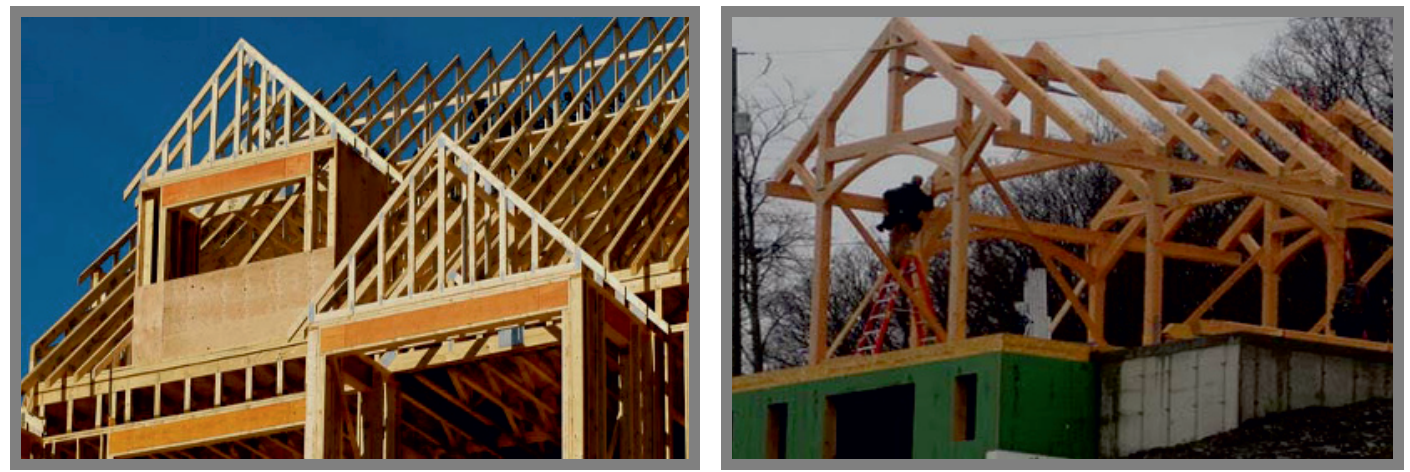

Figure 8. Timber framing system 


\subsection{Block work systems}

This system includes interlocking concrete masonry units (Figure 9) and lightweight concrete blocks.
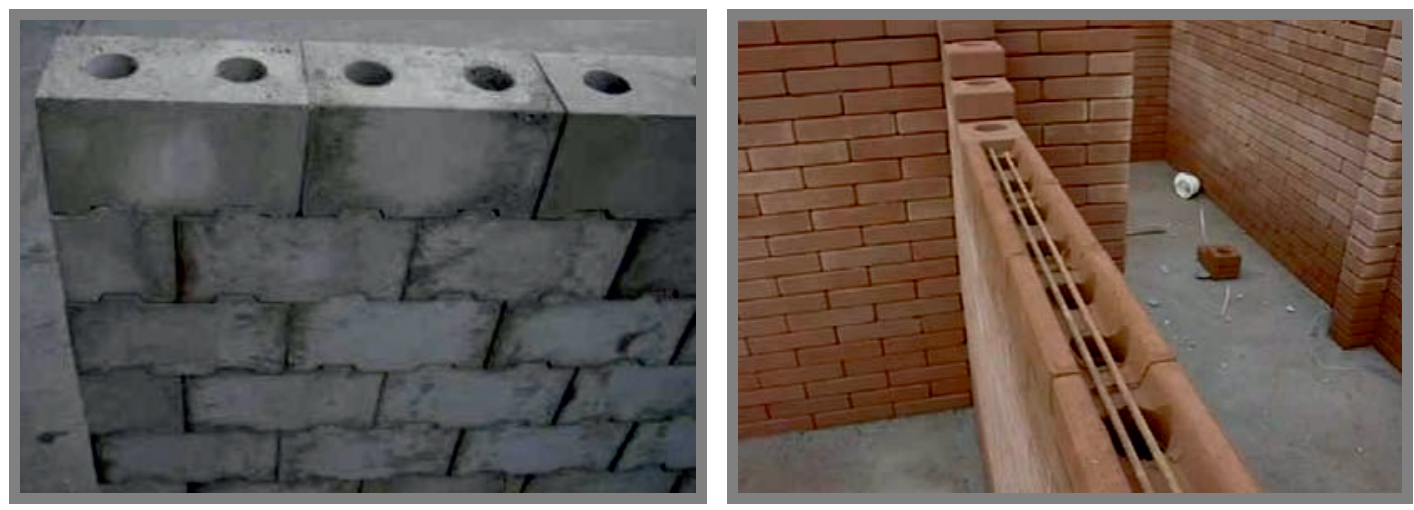

Figure 9. Interlocking block system

\section{Factors that affect the use of the IBS}

The Industrialised Building System which is more commonly known as the IBS among the parties involved in the construction field is a system that is often explained as an approach in building and construction with several limitations [17]. The IBS structure comprises all types of building structures that are generally relevant to the construction industry. The IBS is a construction system where all components are manufactured at the factory beyond the construction site before being placed and installed with minimal installation work at construction sites. The structures are constructed using machines, moulds and other mechanical equipments.

There are several factors that influence the utilisation of the IBS in the construction sector which minimises construction work at the construction site for components that have been already completed at factories and assembly plants. In addition, the equipments at the construction sites can also be reduced. IBS products are of good quality as construction using structural components had assured its strength, even enabling it to be used as strong working platforms. In addition to the other factors that may encourage the usage of the IBS is that its components can be stored for a long time and used for future construction projects that have the same designs with previous construction projects. Construction of the IBS components is conducted according to specifications. These components are built with high observations and accuracies. Another factor that may have led to the IBS being practised at construction sites is the fact that this technology can replace the required frame work. Wall and ceiling surfaces produced using this method is more subtle when compared with traditional methods. Retaining and supporting structures are not necessary any longer because these components will be incorporated into the concrete. Overall, the surface of the pre-cast-concrete is smoother and more refined, so that contractors can proceed with paint jobs without the need for plastering or patching on the exposed surfaces.

\section{Strengths of IBS}

\subsection{Cleaner, neater and safer construction sites}

IBS construction sites have proven to be tidier and better organised as compared to the traditional construction sites which are often wet and dirty. Usages of IBS components can reduce wet work at construction sites. Wastage of time and materials on temporary works such as timber formworks and props, which are common in conventional constructions are reduced greatly when the 
construction emphasises more on IBS components. This prompts construction sites to be neater, reduces involved risks related to health and well-being besides promoting a safer working environment.

\subsection{Able to uphold the sustainability of the environment}

Completion datelines of IBS projects are not that volatile due to the rapid construction rates. In addition, construction operations are not affected because the fabrications of the IBS components are done at factories and in a controlled environment.

\subsection{Cost reduction}

IBS construction methods are cheaper than the traditional method. Savings are made possible when fewer workers are employed as costs can be reduced in terms of wages. The IBS is also considered as one of the cheaper options when considering the overall cost incurred for the construction of a building project. This has brought about the phenomenon where the IBS is now beneficial for the constructions of small shops, offices and simple house designs. It helps if these have easy and repetitive designs. Construction using prefabricated materials can also considerably reduce the usage of scaffoldings and other temporary supports compared to in-situ systems.

\subsection{Reduced Labour}

The construction sector in Malaysia is very much dependent on foreign labour from neighbouring countries like Indonesia, Bangladesh and Vietnam. With the implementation of the IBS system, this dependency can be drastically reduced for the benefit of the local economy. The IBS is able to reduce the number of workers for example concreter, carpenters, bar benders, plasterer and more. Now, the task can be replaced by a group of IBS component installer which at most, may only consist of at least 5 individuals in each project. When the IBS components are produced at factories using complex machineries, it can minimise the requirement of labour and this will lead to savings in terms of labour costs. The usage of IBS will also reduce the required construction site areas and thus contribute to lower budgets.

\subsection{High and controlled quality of end products}

The IBS offer improvements on quality, productivity and efficiency due to the components being factory-produced. It could also reduce the possibilities of poor workmanship and lack of quality control. IBS components have superior quality and better surface finishes compared to that of the traditional method. It provides high quality surface finishes where the joint sections are the only parts to be grouted, eliminating the requirement of plastering. The construction is done in shaded and environmental protected environments which emphasise on critical elements such as material curing processes. Temperature control would be able to evade crack problems on the concrete structures.

\subsection{Faster completion time}

IBS construction projects are able to reduce the construction time periods and this can save valuable time and help to reduce monetary losses. This is because the constructions of prefabricated components are concurrent constructions which can proceed even when the foundations of the construction sites are under survey or when they are involved in earthwork. The installations of IBS components will be made on the sites only after that. This phenomenon helps in reducing the risks of project delays and unnecessary expenditures. IBS element productions are not affected by weather conditions. Instead, the use of large panel structures would be able to accelerate structural-related tasks such as painting, electrical wiring and plumbing. 


\subsection{Not effected by adverse weather conditions}

IBS projects datelines will not be affected thanks to the rapid rates of completion due to the fast construction. In addition, construction operations are not affected because the fabrications of the IBS components are conducted at factories under controlled environments.

\section{Weaknesses of the IBS}

\subsection{High capital costs}

Initial capital costs are usually high. At this stage this includes all costs from the construction of factories, the casting of beds and the acquisition of support machineries which are usually very expensive. Besides that, in some IBS there is a tremendous demand for export labour. Therefore, extra costs are required to train the unskilled or semi-skilled labour.

\subsection{Problem of joints between components}

Malaysia is a country with an equatorial climate. Such countries often experience heavy rainfall during the monsoon seasons every year. This leads to the problem of leakages which is a major problem faced by buildings constructed using IBS applications. When a leakage manifests, other complications may follow and these includes dampness, corrosion and so on.

\subsection{Sophisticated plants and skilled operators}

In the IBS system, extensive usage of sophisticated plants and machineries are involved. These are operated and maintained by skilled operators. If there are any damages to the plants or on the machines, a significant impact will be resulted upon the production of IBS components.

\subsection{Site accessibility}

Site facility and accessibility is one of the most important factors in the implementation of the IBS. The IBS requires adequate access to transport all IBS components of the plants up to the construction sites. It is possible for complications to arise at the construction sites. An example is the delay in the installation of the components due to transportation woes which could result in a delay in the overall construction. The installation task would then have to be performed later.

\subsection{Large Working Area}

Construction projects using the IBS require large work areas for the plants, trailers, tower cranes and storage for the IBS components. In addition, most construction sites, especially those in cities are often crowded and cannot provide the required area.

\section{Conclusions}

A newly encountered obstacle is the traditional mindset of buyers who prefer houses built of brick and mortar. There were erroneous notions and opinions over one of the pre-cast panels where the buyer thinks that it is an element of housing construction of a lower quality because it is regularly used for the construction of low cost housing projects in Malaysia. Due to the ongoing dilemma, developers today are not willing to take the risk to utilise pre-cast construction. Therefore, the parties involved in the construction industry must take the initiative in generating alternative construction methods to compete and remain relevant in the construction industry. Awareness of current trends and 
innovations in the IBS is important. The lack of experience and technical knowledge of contractors regarding the IBS causes the costs to become higher owing to their non-effectiveness in managing the costs. This situation brings about an apprehensive feeling with respect to the efficiency of using an IBS system. Not possessing the suitable technology and relevant experiences pertaining to managing quality problems, productivity as well as safety had caused local contractors being unable to compete with their counterparts in other countries who widely adopt and apply the IBS. So, it is significant for all competitors in the construction industry to ready themselves and begin to takes initiatives in maximising the potentials of their proposed methods of construction. Companies need to play their roles actively to promote changes and to come out with new methodologies to compete with other international competitors. Awareness towards trends and innovations are therefore essential

\section{References}

1. H. Nurul Azam, A.R. Hamzah, H. Mahanim, A Literature Review of the Advantages and Barriers to the Implementation of Industrialied Building System (IBS) in Construction Industry. Malaysian Construction Research Journal, 4 (1) (2009) 10-14.

2. CIDB, IBS Strategic Plan 1999 -2003, Construction Industry Development Board (CIDB), Kuala Lumpur, 1999, pp: 4-6

3. IBS Survey, Construction Industry Development Board Malaysia (CIDB), Kuala Lumpur, 2003

4. A. Kazaz, S. Ulubeyli, A Different Approach to Construction Labour in Turkey: Comparative Productivity Analysis, Journal of Building and Environment, 39 (2004) 93-100.

5. M.R. Abdul Kadir, W.P. Lee, M.S. Jaafar, S.M. Sapuan and A.A.A. Ali, Factors Affecting Construction Labour Productivity for Malaysian Residential Projects, Journal of Structural Survey. 23 (1) (2005) 42-54

6. W.A.M, Thanoon, L.W. Peng, M.R. Abdul Kadir, M.S. Jaafar, M.S Salit, The Experiences of Malaysia and Other Countries in Industrialized Building System in Malaysia, Proceeding on IBS Seminar. UPM, Malaysia, 2003.

7. R. Abdul Rashid, A Model for an Effective Implementation of the Government Technology Transfer Policy in the Malaysian Construction Industry. Unpublished $\mathrm{PhD}$ Thesis. The University of Reading, 1998, 52-80

8. CIDB, IBS Roadmap 2011-2015, Construction Industry Development Board (CIDB), Kuala Lumpur, 2010.

9. CIDB, Construction Industry Master Plan (CIMP 2006-2015). Construction Industry Development Board Malaysia (CIDB). Kuala Lumpur, 2007.

10. K.S. Elliot, Mixed options for Precast Concrete Construction, Building Design and Construction, 2003.

11. Y.F. Badir, M.R. Abdul Kadir, A.H. Hashim, Industrialized Building Systems Construction in Malaysia , Journal of Architectural Engineering, 8 (1) (2002) 19-23

12. E.M. Rojas, P. Aramvareekul, Labor Productivity Drivers and Opportunities in the Construction Industry, Journal of Management in Engineering, 2 (1) (2003) 78-82

13. H.R. Thomas, A.S. Sakarcan, Forecasting Labor Productivity Using Factor Model, Journal of Construction Engineering and Management, 120 (1) (1994) 228-239

14. C.H. Oglesby, H.W. Parker, G.A. Howell, Productivity Improvement in Construction, McGrawHill Inc., Unites State of America, 1989, 5-9

15. P.F. Kaming, P.O. Olomolaiye, G.D. Holt, F.C. Harris, Factors Influencing Craftsmen's Productivity in Indonesia, International Journal of Project Management, 15 (1) (1997) 21-30

16. P.F. Kaming, G.D. Holt, S.T. Kometa and P.O. Olomolaiye. Severity Diagnosis of Productivity Problems - A Reliability Analysis. International Journal of Project Management. 16(2): 107-113 (1998).

17. IBS Roadmap Review, IBS Centre, Construction Industry Development Board, Malaysia, Kuala Lumpur , 2007, pp: 11-15 